BMJ Nutrition,

Prevention \& Health \title{
reduced carbohydrate diet: a qualitative study in family practice \\ Supporting people to implement a
}

To cite: Cupit C, Redman E. Supporting people to implement a reduced carbohydrate diet: a qualitative study in family practice. $B M J$ Nutrition, Prevention \& Health 2021;4:e000240. doi:10.1136/ bmjnph-2021-000240

${ }^{1}$ Department of Health Sciences, University of Leicester, Leicester UK

${ }^{2}$ Diabetes Research Centre, University Hospitals of Leicester NHS Trust, Leicester, UK

Correspondence to

Dr Caroline Cupit, Department of Health Sciences, University of Leicester, Leicester LE1 9RH, UK; caroline.cupit@le.ac.uk

Received 22 January 2021 Revised 21 April 2021 Accepted 24 April 2021 Published Online First 10 May 2021
Check for updates

(C) Author(s) (or their employer(s)) 2021. Re-use permitted under CC BY-NC. No commercial re-use. See rights and permissions. Published by BMJ.

\author{
Caroline Cupit (iD , ${ }^{1}$ Emma Redman ${ }^{2}$
}

\section{ABSTRACT}

Introduction Much of the science behind dietary guidelines for risk reduction and chronic disease management is equivocal, and there are well-accepted uncertainties and complexities relating to diet in everyday life, as well as physiological processes. Guidelines have therefore stopped short of aligning with one particular approach, instead highlighting several evidence-based options. However, reduced carbohydrate, or 'low-carb', diets have increasing traction in the media and with patients, practitioners and the general public. This qualitative study examines healthcare practitioner (HCP) experiences of implementing a reduced carbohydrate diet. Methods Semistructured, qualitative interviews were conducted with 19 HCPs in the UK family practice (including general practitioners, practice nurses and nonmedical practitioners), recruited through a special interest forum, and social media. Data analysis employed social science theory and methods to produce key themes. Results All participants self-identified as 'low-carb practitioners' who, over time, had introduced a specific focus around carbohydrate reduction into their work. They reported transformations in patients' metabolic markers, patient enthusiasm for the approach and renewed job satisfaction. Key themes highlight experiences of: (1) discovering low-carb as a new 'tool-in-the-box'; (2) promoting and supporting incremental low-carb experimentation; and (3) diverging from established dietary guidelines.

Conclusions This study provides important experiencebased evidence on a topical dietary intervention. Participants strongly advocated for the use of low-carb diets. The successes described draw attention to the need for pragmatic, formative evaluation of low-carb advice and support as a 'complex intervention' (alongside physiological research), to justify, challenge and/or shape low-carb intervention in clinical practice. The findings raise important questions about the contribution of particular care practices to the apparent success of lowcarb. Social science analyses can elucidate how dietary intervention is carried out across different healthcare settings (eg, dietetics, endocrinology) and patient groups, how healthcare practices intersect with people's everyday self-management and how different forms of evidence are invoked and prioritised.

\section{INTRODUCTION}

Prior to the advent of pharmacotherapy to manage blood glucose, limiting carbohydrate

\section{What this paper adds}

- Healthcare practitioners in family practice reported that implementing low-carb has transformed many patients' metabolic health—and their own experience of practice.

- Low-carb practitioners were unusually-attentive to patients' diets, adapting models of care to help patients experiment and address tensions between low-carb and dietary guidelines.

- Further research should prioritise pragmatic and formative social-science analyses of low-carb approaches as 'complex interventions' across different healthcare settings and patient groups.

in the diet was the primary method of managing metabolic disorders, most notably diabetes. ${ }^{1}$ Subsequently, pharmacotherapy has taken on a much more prominent role, although modification of diet and lifestyle is still, in principle, a first-line strategy. ${ }^{2}$

Current dietary recommendations promote a person-centred approach, and the same healthy eating advice for people with metabolic conditions (eg, type 2 diabetes) as for the general population': ' $50 \%$ of total dietary energy should be from starchy carbohydrates (such as potatoes, bread and rice), opting for higher fibre or wholegrain versions where possible'. However, since 2011, reduced carbohydrate or 'low-carb' diets, classified as $50-130 \mathrm{~g} /$ day, ${ }^{5}$ have been recognised in UK guidelines as an option for the management of type 2 diabetes-but remain controversial. ${ }^{6-8}$ In response to uncertainties and the increased popularity of this dietary approach, Public Health England commissioned an evidence review by the Scientific Advisory Committee on Nutrition (SACN) ${ }^{9}$ The review was published following a joint working exercise (including the British Dietetic Association (BDA), Diabetes UK and others), ${ }^{9}$ and concluded that there are 'beneficial effects of lower carbohydrate diets for some outcomes (HbAlc, fasting plasma glucose, serum 
triacylglycerol) in the shorter term which are unclear in the longer term'. Over the long term (12+ months), the review found no differential impact on body weight compared with other dietary approaches; impact over the short term was not considered. The report, currently in draft form, also found no harmful effects of carbohydrate restriction in the short term. However, it raised concerns about the impact of low-carb dietary adjustment on micronutrient, saturated fat and fibre intakes-and compatibility with low-fat, wholegrain approaches, which provide the basis for therapeutic, preventative and populationlevel 'healthy eating' advice.

The SACN report highlighted limitations, uncertainties and complexities in the evidence base, many of which are endemic to nutrition science, in which practicalities of undertaking dietary research and funding requirements have impeded long-term 'high quality' trials, and professional consensus. ${ }^{510}$ For example, the report noted: variations in definitions of low-carb and outcomes measured; difficulty in isolating the impact of carbohydrate restriction (specifically) from what could be attributed to weight loss (more generally-and could therefore be achieved with other dietary approaches); lack of studies measuring outcomes beyond $>12$ months. For these same reasons the BDA has resisted aligning with one particular approach. Instead, it has emphasised that dietary support should be focused on weight loss and orientated to individuals' preferences-following the finding that the 'ideal diet is the one that is best adhered to'. ${ }^{\prime 1}$ The BDA has reasserted the importance of professional dietitians as the only regulated healthcare experts in diet and nutrition, [who] should form an integral part of the multidisciplinary team that cares for people with diabetes' ${ }^{7}$

There are an increasing number of healthcare practitioners (HCPs) in other clinical fields, especially family practice, actively promoting carbohydrate restriction for people with type 2 diabetes and the cluster of other related metabolic conditions that are involved in 'metabolic syndrome'. ${ }^{12}$ These HCPs have connected to an international, grass-roots movement of scientists, clinicians and others who, based on their interpretation of the scientific evidence, ${ }^{13-17}$ advocate for low-carb and 'very-low-carb'/ketogenic diets (20-50 g/day) —as a 'superior' ${ }^{18}$ approach with 'untapped potential'. ${ }^{19}$ These advocates have questioned the epidemiological studies on which guidelines such as the Eatwell Guide are based, and drawn attention to the physiological mechanisms involved in the metabolism of dietary components (eg, carbohydrate, cholesterol, saturated fats) and problems of insulin resistance and hyperinsulinaemia. ${ }^{21}$ In the UK, interest in low-carb among HCPs has been spurred by influential general practitioner (GP), David Unwin, ${ }^{22}$ who has observed improvements in patients' metabolic markers in individual case reports and retrospective analyses within his family practice. ${ }^{23}$

Qualitative research is important for investigating the dynamics of food-related healthcare interventionswhich can be characterised as 'complex interventions ${ }^{24}$ due to their multiple elements and potential mechanisms of action. It is crucial to understand how such complex dietary interventions are undertaken, what they involve, how and why they work and for whom. ${ }^{25-28}$ Many such healthcare interventions are developed and adopted in the 'real-world'. This is the case for low-carb intervention, which has evolved as part of grass-roots activity within family practice. A starting point for investigating low-carb intervention is to capture the experiences of stakeholders. ${ }^{29}$ This study provides important experience-based evidence ${ }^{30}$ asking 'What are HCPs' experiences of employing low-carb intervention in family practice?' With low-carb gaining increasing traction, while the scientific evidence remains equivocal and challenging to interpret, ${ }^{31}$ it is crucial to learn from this real-world evidence.

\section{METHODS}

This study explores HCPs' experiences of employing lowcarb information, advice and support in family practicethe site of most first-line support for people with type 2 diabetes, obesity, hypertension and other related metabolic conditions. The data reported are drawn from a larger scoping study of views and experiences of low-carb interventions, which also included HCPs outside family practice, many of whom had not routinely integrated dietary (low-carb) advice into their professional work. This paper reports only the experiences of practitioners offering low-carb interventions in family practice- the main group of respondents.

Participants were recruited via an online special interest forum (200+ UK-based members) and Twitter. As this was an exploratory study, we did not restrict the study to particular HCP roles. Interviews were conducted (with written consent) by the first author, CC, a qualified, experienced social scientist and qualitative researcher, via video or phone during July to August 2020. The topics covered were adapted to the participant, and CC also iteratively drew on past interviews to address emerging areas of interest as the study progressed. Participant accounts were interrogated in detail, and in some cases challenged (drawing on CC's knowledge of scientific debate about low-carb intervention). The focus of interviews was on practitioner experiences and practices, which also included 'shadowed data'-participants discussing the experience of patients. ${ }^{32}$ Data collection was completed when the data set was an appropriate size and quality to meet expectations of rigorous qualitative research-taking account of the scope of the study, nature of the topic, quality of the data and study design. ${ }^{32}$ In relation to the main findings reported in this study, data saturation was achieved. A topic guide is shown in box 1 .

Both data collection and analysis were carried out by CC and drew on social science theory and methods, particularly Smith's mode of enquiry focused on the 


\section{Box 1 Qualitative interview topic guide}

Topic guide

- How was the participant introduced to low-carb and why/how are they promoting in practice (or not)?

- What types of low-carb dietary approaches are being promoted? (eg, What constitutes 'low-carb' in practice?).

- Which patient groups are being targeted?

What rationales are being used as the basis for implementation?

- How are healthcare practitioners (HCPs) promoting and supporting low-carb approaches in practice? (eg, resources, behavioural techniques, organisations involved).

- What are HCPs' experiences of promoting and supporting patients with low-carb? (eg, What successes and/or obstacles have they and their patients experienced?).

- How are HCPs making sense of the science of low-carb and the scientific controversies-personally, and in their interactions with patients and colleagues?

- How does the low-carb approach fit with guidelines, previous practice and colleagues' current practice?

'social organisation' of people's knowledge and practices. ${ }^{33}$ This approach is particularly useful to interrogate different forms of knowledge, everyday practices and the coordinating institutional systems involved; it provides conceptual and methodological tools to foreground what happens in practice even when the research is reliant on interview, rather than observational, data. ${ }^{34}$ In keeping with this approach, interviews (audio recorded and transcribed) tracked HCPs' knowledgeable practices in preference to capturing their opinions on contemporary dietary debates. Studies using a similar methodological approach have shown that, when HCPs are questioned about the practical details of what they do and say rather than being asked only about their opinions, their accounts align well with both patients' accounts and observations of practice. ${ }^{35}$

Analysis began with writing summary field notes after each interview (noting particular areas of interest), reading transcripts and reviewing recordings (for data immersion and clarification). Types of activity were coded and indexed (presented here as 'themes' but produced within Smith's theoretical approach). Analysis was carried out July to October 2020 and was based on CC's reflective and thoughtful engagement with the data and the analytical process. ${ }^{36}$ This included searching for unusual or contradictory evidence across the data set, and presenting/discussing findings with academic colleagues and research participants. NVivo software was used to store transcripts and aid data retrieval and analysis.

Findings reflect the knowledge and experience of lowcarb practitioners, as they articulated them. As is usual in qualitative research, participants' accounts (reporting how they act, and what they say) have not been verified as factually accurate, and the excerpts provided also include generalisations and simplifications. However, participants' accounts were interrogated and challenged during interview, and examined for consistency. Interview techniques (eg, focusing on practices rather than opinions) were used to minimise the impact of cognitive bias, but this cannot be eliminated. These findings therefore answer questions about practitioners' knowledge and experiences of low-carb intervention; further work would be required to elucidate how these accounts align with observations of practice or with the perspectives of patients.

CC had no personal or professional ties with participants, personal experience of low-carb diets or academic/financial conflict of interest. CC consciously reflected on potential biases, seeking out published and popular critique of the low-carb approach throughout the study.

\section{RESULTS}

Nineteen interviews were carried out with HCPs in family practice with experience of delivering low-carb support (GPs $\mathrm{n}=13$; practice nurses $\mathrm{n}=3$; employed health coaches $\mathrm{n}=1$; 'Volunteer Health Coaches' $\mathrm{n}=2$ (male $\mathrm{n}=10$; female $\mathrm{n}=9)$ ). The role described here as 'Volunteer Health Coach' was undertaken by unpaid HCPs who had undertaken the Public Health Collaboration's Ambassadors Programme. Most participants had many years of clinical experience. All participants advocated for low-carb as a first-line approach for the treatment of metabolic conditions relating to metabolic syndrome (eg, type 2 diabetes). For this reason, we describe the participant group here as 'low-carb practitioners', even though the extent to which they had integrated low-carb intervention into their work varied.

It is important to note that all the participants in this study were positive about their experience of advising and supporting a low-carb intervention. Despite efforts to recruit HCPs with negative experiences of integrating low-carb into their practice, none were forthcoming. CC also observed contemporary debates about low-carb over $\sim 5$ years, including following discussion in news/social media. From this we believe that there is unlikely to be a significant residual group of practitioners (with divergent experiences of providing low-carb interventions) who failed to respond to the study invitation. We consider the participant sample to be broadly representative of the experiences of early-adopter low-carb practitioners.

Key findings outlined below highlight low-carb practitioners' perceptions and experiences of: (1) discovering low-carb as a new 'tool-in-the-box'; (2) promoting and supporting incremental low-carb experimentation; and (3) deviating from established dietary guidelines. Illustrative excerpts mapping to these themes are provided in the sections below and in tables 1-3. All interview excerpts are anonymised.

\section{Discovering low-carb as a new 'tool-in-the-box'}

Low-carb practitioners talked about having 'discovered' the low-carb approach, and coming to believe in its superiority when compared with other interventions for people 
Table 1 Discovering low-carb as a new 'tool-in-the-box'-interview excerpts

\section{Reference No Interview excerpt}

\begin{tabular}{|c|c|}
\hline 1.01 & $\begin{array}{l}\text { [The patient] came back to see me having gone from an HbA1c of like } 90 \text {-something, down to } 33 \text { I think. And } \\
\text { I was like 'oh wow, well done', and he gave me Michael Mosley's book. And that triggered kind of a really } \\
\text { obvious connection between food and blood sugar that I hadn't, embarrassingly [considered]. It's just so } \\
\text { overlooked, isn't it? (PN03) }\end{array}$ \\
\hline 1.02 & $\begin{array}{l}\text { I was a lot bigger [12 years ago]. I was about } 20 \text { stone then, so I started low-carb [...] and lost loads of weight. } \\
\text { And I had polycystic ovaries and insulin resistance, and I did it for that reason as well. (PN16) }\end{array}$ \\
\hline 1.03 & $\begin{array}{l}\text { I spent two years just reading as much as I could, going to conferences, listening to podcasts. So just } \\
\text { immersing myself. It was the most exciting thing l've ever done in my career. (GP17) }\end{array}$ \\
\hline 1.04 & $\begin{array}{l}\text { I've been diabetic lead for the practice for } 18 \text { years. I pushed [patients to manage their conditions] but I } \\
\text { watched them get worse, I watched } 200 \text { diabetics become } 400 \text { diabetics, and I didn't do a single thing that } \\
\text { made a difference. I didn't reverse a single case of diabetes. Low-fat doesn't work, full stop. (GP14) }\end{array}$ \\
\hline 1.05 & $\begin{array}{l}\text { Before I came to this, I'd been doing the diabetes clinics for three or fouryears, and it was all about drugs, and } \\
\text { I wasn't that excited about diabetes. [...] When patients would ask me 'what shall I eat, doctor?', I'd sort of } \\
\text { avoid the conversations, because I didn't have a good answer, apart from 'everything in moderation'. (GP17) }\end{array}$ \\
\hline 1.08 & $\begin{array}{l}\text { I had another patient who is diabetic, or not diabetic anymore-she's in remission. She had non-fatty liver } \\
\text { disease as well, and arthritis in her knees. She went for a scan, and [her liver's] completely clear. And the } \\
\text { doctor actually said 'this is not possible!' She was like 'yeah, I've done it through diet'. So she's got no fatty- } \\
\text { liver anymore, her arthritis has gone in her knees, and her diabetes is in remission. So, and that's just through } \\
\text { food-it's amazing. (PN15) }\end{array}$ \\
\hline 1.09 & $\begin{array}{l}\text { My [GP] partner and I have found that this is a completely and utterly joyful way of doing medicine. We used } \\
\text { to joke about our exit plan. [...] We now tell people how liberating it is to practice medicine like this. You've got } \\
\text { people coming into your room saying 'I can't lose weight', that's a heart-sink, 'I've got chronic pain, irritable } \\
\text { bowel, I've got reflux, diabetes I can't control'. Now all of a sudden we have this magnificent tool in the box. } \\
\text { It's completely changed our lives as practitioners. (GP02) }\end{array}$ \\
\hline
\end{tabular}

with type 2 diabetes and related metabolic conditions. They used the term 'low-carb' loosely, typically employing widely circulated definitions of 'low-carb' and 'very-lowcarb $^{, 5}$ to guide advice and support towards a daily carbohydrate intake of $\sim 20-130 \mathrm{~g}$ although these amounts were not necessarily shared with patients, or measurement advocated.

Most low-carb practitioners in this study had investigated the science behind dietary intervention, and specifically engaged with the low-carb movement through (for example) journal publications, conference talks, social media and podcasts. Some had been introduced to lowcarb by a patient (No 1.01) or following their own metabolic conditions (table 1 ).

Several low-carb practitioners described personal experience of weight loss and other health benefits from low-carb (No 1.02). All had connected into an informal network of professionals using low-carb, and undertaken online research. Although they had some previous understanding of the fundamental physiology involved from medical curricula, the way in which the science was interpreted (in relation to the management of metabolic conditions) was new and, they found, compelling (No 1.03). However, this application of the science was inconsistent with their own prior knowledge, and the advice they had been giving to patients over many years (No 1.04, No 1.05)—providing different insights to those derived solely from epidemiological studies and interventional trials. Scientists and others within the low-carb movement proposed metabolic mechanisms to which the participants in this study had not previously given much attention, but which intuitively 'made sense' (No 1.06). These HCPs had gradually incorporated low-carb into their clinical practice, usually first experimenting with receptive and interested patients, and accumulating a database of their own 'results', of which most kept independent records to sit alongside the publicised successes of pioneers such as David Unwin. They had come to believe low-carb was a superior approach to other potential options, for most patients with metabolic conditions. Local successes built their own enthusiasm to discuss lowcarb options with patients (No 1.07).

Low-carb practitioners gave many examples of patients who had made significant changes to their metabolic health markers (and summary statistics/audits from their own practices). Many of these had experienced metabolic inconsistencies for many years but had managed, with lowcarb, to improve their lives in ways that were profoundly 
Table 2 Promoting and supporting incremental low-carb experimentation

\begin{tabular}{|c|c|}
\hline Reference No & Interview excerpt \\
\hline 2.01 & $\begin{array}{l}\text { I give more of a real-food stance to it. It's having whole-foods and not processed-foods-they tend to be the } \\
\text { lower carb foods really. (PN15) }\end{array}$ \\
\hline 2.04 & $\begin{array}{l}\text { On the Weight Watchers programme l'd lost a bit of weight, and then when I switched to [low-carb] I rapidly } \\
\text { lost } 15 \text { kilograms without trying, and for the first time in my life hunger left me. (GP24) }\end{array}$ \\
\hline 2.05 & I ask patients 'what foods do you think spike your blood glucose?' (HC08) \\
\hline 2.06 & [For weight-loss] 'We need to get you into fat-burning mode, so to do that we have to get insulin down.' (GP06) \\
\hline 2.09 & $\begin{array}{l}\text { It's about [patients] figuring out: how low can they go? what does that do for their blood sugar? I say 'just go } \\
\text { away and play detective for a week, here's a blood sugar machine, write down everything [...]. Do you want to } \\
\text { push it further? If not, OK... (GP17) }\end{array}$ \\
\hline
\end{tabular}

meaningful to them (No 1.08). These successes included 'uncomplicated' patients and those with multiple conditions and extensive psychological/social barriers to making dietary changes. The job satisfaction that these successes afforded led to transformed experiences of clinical practice from constant 'heart-sink' situations to 'joyful' practice (No 1.09). Low-carb practitioners were encouraged by patient successes and the opportunity to use limited resources better.

\section{Promoting and supporting incremental low-carb experimentation}

Low-carb practitioners framed low-carb as a new, but sustainable, way of eating - in contrast to highcarbohydrate eating and/or short-term diets for weight loss which were presented as 'disordered' (unhealthy, unnatural or unsustainable). Their advice to patients started with 'real-food' messages, avoiding processed foods such as breakfast cereals (No 2.01) and focusing on carbohydrate reduction from what was frequently a very high baseline (No 2.02) (see table 2).

Low-carb practitioners understood the concept of 'realfood' as a useful first step for patients to reduce carbohydrates (often represented as traditional food using whole/intact and diverse ingredients ${ }^{37}$ ). They felt that these messages were easy to understand, largely uncontroversial in society and avoided conflict with the advice of other healthcare professionals. They described working with patients to support their personal goals especially avoiding intensification of medication, and achieving weight loss. The low-carb way of eating was not presented as overly restrictive, and low-carb practitioners did not usually recommend 'carb counting' by standard definitions, ${ }^{38}$ despite often suggesting the elimination of major sources of carbohydrate such as wheat flour, pasta, rice, potatoes. One of ways they presented the benefits of lowcarb, they said, was that people would feel good and not have to go hungry (No 2.03, No 2.04). They described using simple physiological explanations to help patients understand and implement the approach (No 2.05, No 2.06, No 2.07). The aim was for meaningful and sustained metabolic improvement, encouraged by tangible metabolic evidence (No 2.08). Patients were routinely encouraged to experiment using blood sugar monitors along with food records (No 2.09).

Low-carb practitioners talked about employing a range of resources, notably sugar infographics demonstrating how carbohydrate-rich foods are broken down into sugar in the body, ${ }^{39}$ real food/fake food pictures, insulin rollercoaster illustrations (showing the impact of carbohydrates on blood sugar and insulin levels) and diet sheets with links to online resources. These had often originated with low-carb pioneers (who had freely shared them), while others were created to meet the needs of particular patient demographics. Inspirational case studies (eg, records of patient successes on consulting room walls) were also widely discussed. Many low-carb practitioners initiated discussion of meal planning with patients (eg, in relation to vegetarian/cultural diets) to support experimentation.

In addition to promoting low-carb in individual consultations, most low-carb practitioners had established support groups, many of which were reported as the 
Table 3 Diverging from established dietary guidelines

\section{Reference No Interview excerpt}

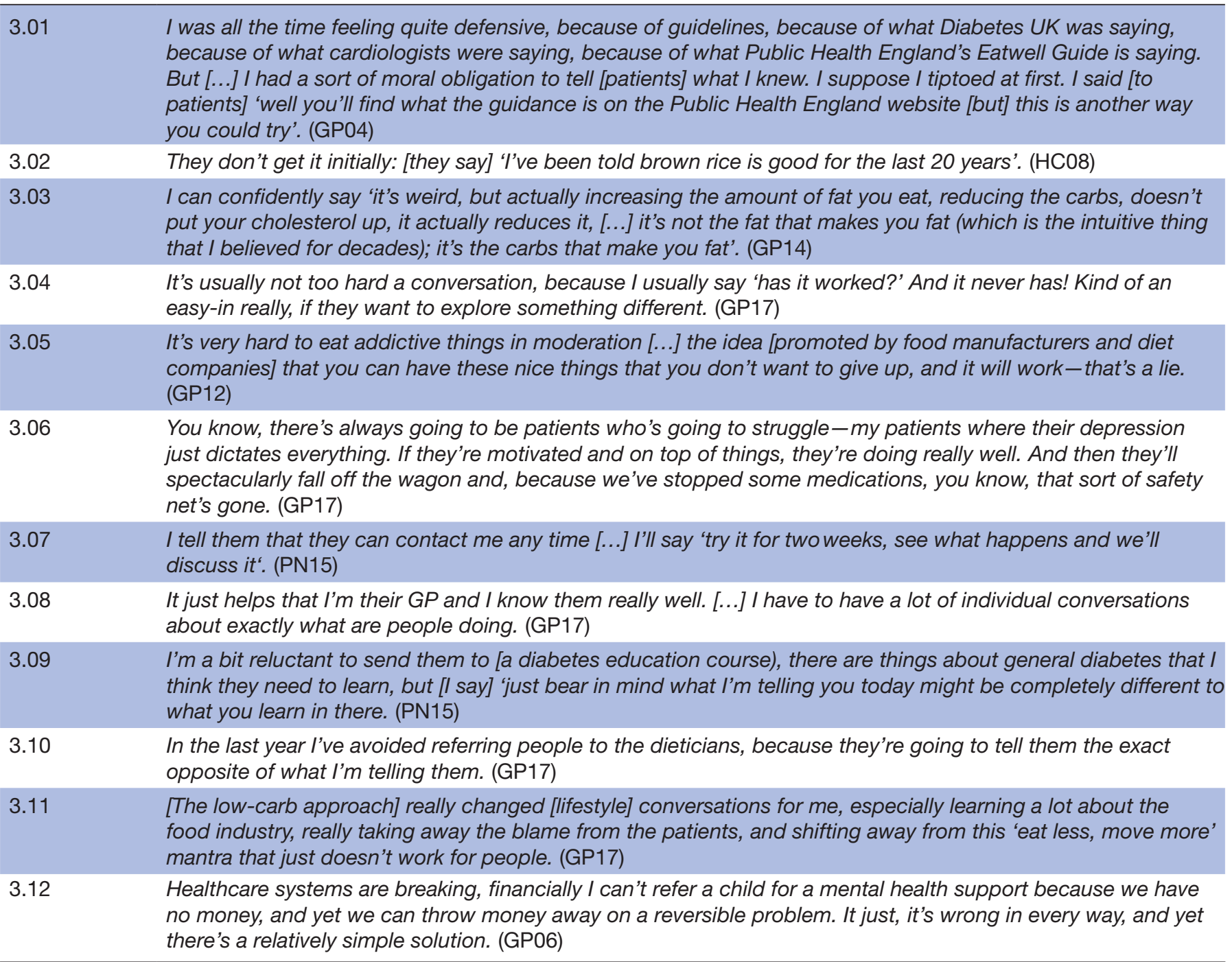

catalyst for significant metabolic health improvements. These group sessions were variously organised, but were usually informal without a standardised format or restrictive eligibility criteria. They enabled presentations of the underpinning science and examples from practice, along with ongoing and flexible peer support among patients (particularly around psychosocial aspects of eating and/ or short-term side effects of a low-carb diet). Several practices used Public Health Collaboration's Ambassadors Programme ('Volunteer Health Coaches') to run these groups. Many had been transferred (or initiated) online due to COVID-19 restrictions.

\section{Diverging from established dietary guidelines}

Low-carb practitioners were convinced by the scientific evidence supporting low-carb as a first-line intervention, and felt under a moral obligation to share their knowledge about low-carb with patients. However, low-carb practitioners were concerned about tensions between low-carb and more established dietary interventions, which had become embedded in guidelines over the last 40 years. For this reason, some reported 'tiptoeing' when introducing low-carb into clinical practice, being careful about how they navigated healthy eating guidelines (No 3.01), and limiting low-carb advice to patients with type 2 diabetes and/or obesity, for whom the evidence was strongest (see table 3).

Tensions routinely emerged between the low-carb approach and established dietary guidelines such as the Eatwell Guide (No 3.01). For example, low-carb practitioners believed the Eatwell Guide undermined 'realfood' messages with pictures of breakfast cereals, bread, margarine and low-fat dairy products.

Promoting low-carb required that practitioners respond to established dietary knowledge as presented to them by patients (No 3.02). In particular, replacing carbohydrates with dietary fats/protein created particular dissonance (No 3.03). A typical way of handling such queries, HCPs reported, was to question whether previous approaches 
had 'worked' (No 3.04). Low-carb practitioners reported that low-carb was often difficult for patients within a highcarbohydrate food environment in which 'treats' and 'all-things-in-moderation' are encouraged. They reported that some patients who were 'addicted' to carbs/sugar were advised to take a particularly rigorous approach to cutting carbohydrate (No 3.05).

HCPs reported that by following low-carb inconsistently there were risks of medication side effects (No 3.06). Low-carb practitioners talked about relying on closer monitoring than was established within chronic disease management systems to mitigate against clinical harms (and consequent complaints) - for example, from hypoglycaemia, when managing glucose-lowering medications alongside carbohydrate reduction. They described asking patients to communicate directly with them, instead of following usual appointment processes (No 3.07, No 3.08). They reported tensions with some other clinicians and often organised dietary support 'in-house' rather than referring to dietitians-or carefully highlighted differences with other HCPs, in order to reduce confusion for patients (No 3.09, No 3.10). Although low-carb practitioners varied in their willingness to directly criticise established and dominant dietary knowledge, most found that highlighting food/pharmaceutical involvement in the production of evidence/guidelines combated patients' feelings of shame in relation to their inability to make changes (No 3.11). They described frustration with institutional systems (and organisations such as National Institute for Health and Care Excellence) that were seen to resist potentially transformative scientific and practicebased evidence (No 3.12).

\section{DISCUSSION}

This study uniquely documents the experiences of a growing movement of HCPs in family practice who are promoting low-carb as a first-line (and superior) treatment for metabolic conditions-especially type 2 diabetes and other conditions involved in metabolic syndrome. We have described this group of HCPs as 'low-carb practitioners', in line with how they self-identified and associated with the low-carb movement of scientists, clinicians, patients and others promoting low-carb for metabolic health improvement. Their shift to promoting low-carb options was apparently driven by their frustration with what they perceived to be ineffectual established interventions and guidance. As a result of this they had sought alternatives from outside the established channels for evidence-based practice and professional development. As front-line primary care HCPs, most low-carb practitioners regretted their lack of training in nutrition.

Low-carb practitioners' accounts challenge dominant contemporary narratives that attribute the ineffectiveness of lifestyle interventions to patients' lack of adherence,${ }^{40-42}$ and/or focus on practitioners' unwillingness to discuss diet/weight. ${ }^{43}$ Participants in this study compared low-carb with other approaches that they had recommended previously (eg, Eatwell Guide healthy eating guide, commercial weight loss programmes). Their perception was that for many people previous adherence had not led to improvement in key markers of healthwhich had discouraged them from proactively addressing diet with patients. These early adopters of low-carb intervention contended that low-carb 'works'-that is, as an evidence-based strategy for self-management-and that they had witnessed improvements in their patients' metabolic health. The findings are consistent with a previous survey of patient experiences of low-carb intervention. ${ }^{44}$

Low-carb practitioners had become highly enthusiastic about initiating conversations about diet with patients and supporting dietary change. This finding is a notable point of difference with other studies that have conversely highlighted that HCPs in family practice tend to avoid conversations about diet and exercise with patients because of the perceived sensitivities of discussing lifestyle/weight, ${ }^{43}$ as well as institutional factors such as limited nutrition education in clinical curricula, ${ }^{45}$ short appointment times ${ }^{46}$ and incentives that drive pharmaceutical interventions. ${ }^{35}$ Low-carb practitioners reported personally monitoring patients, explaining physiology ${ }^{47}$ and discussing the social complexities of everyday eating as part of consultations, in a way they had not undertaken previously. ${ }^{26}$ Such care practices are known to be valued by patients, ${ }^{48}$ but are increasingly constrained within the severe pressures of UK family practice.

Concerns have been raised over implementation and sustainability of low-carb in patients' everyday selfmanagement practice. $^{49}$ In this study, low-carb practitioners reported that they supported patients to incrementally experiment with low-carb eating-encouraging them to be as radical as was manageable in light of their current diet and everyday life, assuring them that health improvement would follow and facilitating active monitoring of improvement in relation key health markers. Practitioners' accounts indicated that, although some patients required only a prompt and minimal clinical intervention, for others more attentive support was required. They noted that patients from a wide range of socioeconomic and cultural backgrounds were able to implement the approach and sustain it over months and years-although with various challenges. Particular attention was required to ensure medication safety when patients made dramatic and/or sudden reductions to their dietary carbohydrates.

The low-carb approach observed in family practice can be defined as a 'complex intervention' 2429 involving different elements-not only low-carb as a dietary technology (ie, the nutritional profile recommended to patients). Our findings indicate that low-carb practitioners generated positive therapeutic relationships with patients, established models for support (eg, peer support groups, personal email support) and that these changes may have contributed to patients adopting/adhering to broadly defined 'healthy eating' behaviours. ${ }^{50}$ Participants, however, contended that the key mechanism for 
impact was the low-carb dietary technology, and that the development of supplementary care practices had been inspired by this low-carb component.

This study foregrounds the importance of social science studies of dietary interventions. It has highlighted the experiences of HCPs who have adopted the low-carb approach, and the transformative impact on practice that they report. This is important experience-based evidence $^{30}$ that can inform the development of further research, and ultimately help ensure that patients with markers of poor metabolic health have access to support that meets their needs. Further research on low-carb interventions should involve biomedical studies of clinical effectiveness and harms, and pragmatic, formative process evaluations of how they are being implemented in practice, ${ }^{29}$ including the feasibility, appropriateness and meaningfulness of intervention. ${ }^{51}$ It should explore different models of support, including the various technologies and care practices involved (eg, blood glucose monitoring systems; peer support groups; educational materials and messaging; and online/digital support).

Crucially, further research should map different forms of knowledge about diet and nutrition, sources of evidence and how low-carb fits (or does not fit) within the broader institutional structures delivering dietary support. It should ensure that the experiences of a wide range of different stakeholders are captured-including people with different conditions, from different sociodemographic backgrounds and those that have resisted or struggled with the approach. The 'shadowed data' reported here (experiences of patients, as reported by practitioners $^{32}$ ) also point to other important avenues for further investigation (eg, dietary 'habits', carb 'addiction', disordered eating ${ }^{52}$ ) that may help address persistent questions about sustainability of low-carb eating and potential harms of low-carb when implemented in everyday life. ${ }^{53}$

\section{STRENGTHS AND LIMITATIONS}

This study uniquely documents the perceptions and experiences of low-carb practitioners in family practice, including reported improvements in patients' metabolic markers. It reports low-carb practitioners' own accounts of their practices, and does not attempt to externally verify their experiences, or address quantitative outcomes of low-carb interventions-despite many participants sharing statistics from their own records in interviews. The findings reported here are predominantly from GP interviews, reflecting the data sample, and the dominance of GPs among early adopters of low-carb interventions in family practice.

\section{CONCLUSIONS}

In the context of controversies around how the scientific evidence base for dietary intervention can be interpreted and applied, this study provides important experience-based evidence on a topical dietary intervention. Low-carb practitioners strongly advocated for the use of low-carb diets in the management of people with type 2 diabetes and related metabolic conditions. The successes described draw attention to the need for pragmatic, formative evaluation of low-carb as a "complex intervention' (alongside physiological research), to justify, challenge and/or shape low-carb intervention in clinical practice. Social science analyses would elucidate how this intervention is carried out across different healthcare settings (eg, dietetics, endocrinology) and patient groups, how healthcare practices intersect with people's everyday self-management and how different forms of evidence are invoked and prioritised.

\section{Twitter Caroline Cupit @CarolineCupit}

Acknowledgements The author is grateful to all participants for their contribution to this study, and to academic colleagues who offered constructive critique on this paper during its development.

Contributors CC planned the study, undertook data collection and analysis, and drafted, reviewed, edited and submitted the manuscript. ER provided advice relating to diet/nutrition and reviewed and edited the manuscript.

Funding This work was supported by CC's Mildred Blaxter Postdoctoral Fellowship from the Foundation for the Sociology of Health and Illness.

Disclaimer The funder had no part in data collection, analysis or reporting.

Competing interests ER is in receipt of funding from the NIHR/Department of Health as Operations Manager for the NIHR Diet and Activity Research Translation Collaboration.

Patient consent for publication Not required.

Ethics approval The study was approved by University of Leicester Medicine and Biological Sciences Research Ethics Committee (25905).

Provenance and peer review Not commissioned; externally peer reviewed by $\mathrm{Dr}$ Campbell Murdoch, Millbrook Surgery, England.

Data availability statement All data relevant to the study are included in the article or uploaded as supplementary information. Deidentified interview transcripts are stored in accordance with the University of Leicester governance procedures. These are not publicly available in order to protect the confidentiality of participants.

Open access This is an open access article distributed in accordance with the Creative Commons Attribution Non Commercial (CC BY-NC 4.0) license, which permits others to distribute, remix, adapt, build upon this work non-commercially, and license their derivative works on different terms, provided the original work is properly cited, appropriate credit is given, any changes made indicated, and the use is non-commercial. See: http://creativecommons.org/licenses/by-nc/4.0/.

ORCID iD

Caroline Cupit http://orcid.org/0000-0002-3377-8471

\section{REFERENCES}

1 Humphrey L. A Manual of Nursing : Medical and Surgical. P. Blakiston, Son, and Co., Philadelphia, 1890, 1892. Available: https://www.amazon.com/Manual-Nursing-Medical-Surgical/dp/ B00CLFOKJO/ref=tmm_hrd_title_3?_encoding=UTF8\&qid=\&sr=

2 NICE. Type 2 diabetes in adults: management (updated 2020). NICE, 2015. Available: https://www.nice.org.uk/guidance/ng28 [Accessed 19 Apr 2021]

3 Public Health England. The Eatwell guide booklet. GOV.UK, 2016. Available: https://www.gov.uk/government/uploads/system/uploads/ attachment_data/file/551502/Eatwell_Guide_booklet.pdf [Accessed 16 Sep 2016].

4 Public Health England. SACN consultation on lower carbohydrate diets for people with type 2 diabetes, 2020. Available: https://www. gov.uk/government/news/sacn-consultation-on-lower-carbohydratediets-for-people-with-type-2-diabetes [Accessed 12 Oct 2020]. 
5 Feinman RD, Pogozelski WK, Astrup A, et al. Dietary carbohydrate restriction as the first approach in diabetes management: critical review and evidence base. Nutrition 2015;31:1-13.

6 Davies MJ, D'Alessio DA, Fradkin J, et al. Management of hyperglycemia in type 2 diabetes, 2018. A consensus report by the American diabetes association (ADA) and the European association for the study of diabetes (EASD). Diabetes Care 2018;41:2669-701.

7 British Dietetic Association. Low carbohydrate diets for the management of type 2 diabetes in adults: policy statement, 2018. Available: https://www.bda.uk.com/resource/low-carbohydrate-dietsfor-the-management-of-type-2-diabetes-in-adults.html [Accessed 26 Aug 2020].

8 Dyson P. Very low carbohydrate ketogenic diets and diabetes. Pract Diab 2020;37:121-6.

9 Scientific Advisory Committee on Nutrition on behalf of Public Health England. Lower carbohydrate diets for adults with type 2 diabetes: draft report from a working group, 2020. Available: https://assets. publishing.service.gov.uk/government/uploads/system/uploads/ attachment_data/file/860659/Draft_diabetes_report.pdf [Accessed 12 Oct 2020].

10 Diabetes UK. Evidence-Based nutrition guidelines for the prevention and management of diabetes, 2018. Available: https://www.diabetes. org.uk/professionals/position-statements-reports/food-nutritionlifestyle/evidence-based-nutrition-guidelines-for-the-prevention-andmanagement-of-diabetes [Accessed 14 Sep 2020].

11 Johnston BC, Kanters S, Bandayrel K, et al. Comparison of weight loss among named diet programs in overweight and obese adults: a meta-analysis. JAMA 2014;312:923-33.

12 Alberti KGMM, Zimmet P, Shaw J, et al. The metabolic syndrome--a new worldwide definition. Lancet 2005;366:1059-62.

13 Kelly T, Unwin D, Finucane F. Low-Carbohydrate diets in the management of obesity and type 2 diabetes: a review from clinicians using the approach in practice. Int J Environ Res Public Health 2020;17:2557.

14 Hite AH, Berkowitz VG, Berkowitz K. Low-Carbohydrate diet review. Nutr Clin Pract 2011;26:300-8.

15 Astrup A, Magkos F, Bier DM, et al. Saturated Fats and Health: A Reassessment and Proposal for Food-Based Recommendations: JACC State-of-the-Art Review. J Am Coll Cardiol 2020;76:844-57.

16 Castro-Barquero S, Ruiz-León AM, Sierra-Pérez M, et al. Dietary strategies for metabolic syndrome: a comprehensive review. Nutrients 2020;12:2983.

17 Tay J, de Bock MI, Mayer-Davis EJ. Low-carbohydrate diets in type 2 diabetes. Lancet Diabetes Endocrinol 2019;7:331-3.

18 Feinman RD. The biochemistry of low-carbohydrate and ketogenic diets. Curr Opin Endocrinol Diabetes Obes 2020;27:261-8.

19 Westman EC. Editorial: Exploring the untapped potential of low-carbohydrate diets. Curr Opin Endocrinol Diabetes Obes 2020;27:253-4.

20 Lustig R. Fat chance: the hidden truth about sugar, obesity and disease. London: Fourth Estate Ltd, 2014.

21 Fung DJ, Noakes T. The obesity code: unlocking the secrets of weight loss. 1st edn. Vancouver, Canada: Greystone Books, 2016.

22 Pulse Today. Power 50 GPs 2018: no 9, DR David Unwin. pulse today, 2018. Available: http://www.pulsetoday.co.uk/news/hottopics/pulse-power-50-2018/9-dr-david-unwin/20037230.article [Accessed 1 Aug 2019].

23 Unwin D, Khalid AA, Unwin J, et al. Insights from a general practice service evaluation supporting a lower carbohydrate diet in patients with type 2 diabetes mellitus and prediabetes: a secondary analysis of routine clinic data including $\mathrm{HbA1c}$, weight and prescribing over 6 years. BMJ Nutr Prev Health 2020;3:bmjnph-2020-000072.

24 Craig P, Dieppe P, Macintyre S, et al. Developing and evaluating complex interventions: the new medical Research Council guidance. BMJ 2008;337:a1655.

25 Harris JE, Gleason PM, Sheean PM, et al. An introduction to qualitative research for food and nutrition professionals. J Am Diet Assoc 2009;109:80-90.

26 Bisogni CA, Jastran M, Seligson M, et al. How people interpret healthy eating: contributions of qualitative research. J Nutr Educ Behav 2012;44:282-301.

27 Swift JA, Tischler V. Qualitative research in nutrition and dietetics: getting started. J Hum Nutr Diet 2010;23:559-66.
28 Pilnick A, Swift JA. Qualitative research in nutrition and dietetics: assessing quality. J Hum Nutr Diet 2011;24:209-14.

29 Evans R, Scourfield J, Murphy S. Pragmatic, formative process evaluations of complex interventions and why we need more of them. J Epidemiol Community Health 2015;69:925-6.

30 Green LW. Making research relevant: if it is an evidence-based practice, where's the practice-based evidence? Fam Pract 2008;25 Suppl 1:i20-4.

31 Williams CM, Ashwell M, Prentice A. Nature of the evidence base and frameworks underpinning dietary recommendations for prevention of non-communicable diseases: a position paper from the Academy of nutrition sciences. Br J Nutr 2020;58:1-15.

32 Morse JM. Determining sample size. Qual Health Res 2000;10:3-5.

33 Smith DE. Institutional ethnography as practice. Rowman \& Littlefield, 2006.

34 Cupit C, Rankin J, Armstrong N. Taking sides with patients using institutional ethnography. J Organ Ethnogr 2021.

35 Cupit C, Rankin J, Armstrong N, et al. Overruling uncertainty about preventative medications: the social organisation of healthcare professionals' knowledge and practices. Sociol Health IIIn 2020;42 Suppl 1:114-29.

36 Braun V, Clarke V. Reflecting on reflexive thematic analysis. Qual Res Sport Exerc Health 2019;11:589-97.

37 Planck N. Real Food: What to Eat and Why. Reprint edition. New York: Bloomsbury Publishing PLC, 2007.

38 Low Carb Program. Does low-carb mean no-carb? 2019. Available: www.lowcarbprogram.com [Accessed 9 Sep 2020].

39 Unwin D. Sugar equivalent Infographics. public health Collab, 2020. Available: https://phcuk.org/sugar/ [Accessed 26 Aug 2020].

40 Murray J, Fenton G, Honey S, et al. A qualitative synthesis of factors influencing maintenance of lifestyle behaviour change in individuals with high cardiovascular risk. BMC Cardiovasc Disord 2013;13:48.

41 Bombak AE, Riediger ND, Bensley J, et al. A systematic search and critical thematic, narrative review of lifestyle interventions for the prevention and management of diabetes. Crit Public Health 2020;30:103-14

42 Thomas SL, Hyde J, Karunaratne A, et al. "They all work.when you stick to them": a qualitative investigation of dieting, weight loss, and physical exercise, in obese individuals. Nutr J 2008;7:34.

43 Blackburn M, Stathi A, Keogh E, et al. Raising the topic of weight in general practice: perspectives of GPs and primary care nurses. BMJ Open 2015;5:e008546.

44 Cucuzzella MT, Tondt J, Dockter NE. A low-carbohydrate survey : evidence for sustainable metabolic syndrome reversal. J Insul Resist 2017;2:1-25

45 Mogre V, Stevens FCJ, Aryee PA, et al. Why nutrition education is inadequate in the medical curriculum: a qualitative study of students perspectives on barriers and strategies. BMC Med Educ 2018;18:26.

46 Gianfrancesco C, Johnson M. Exploring the provision of diabetes nutrition education by practice nurses in primary care settings. $J$ Hum Nutr Diet 2020;33:263-73.

47 Breen C, McKenzie K, Yoder R, et al. A qualitative investigation of patients' understanding of carbohydrate in the clinical management of type 2 diabetes. J Hum Nutr Diet 2016;29:146-55.

48 Stenner KL, Courtenay M, Carey N. Consultations between nurse prescribers and patients with diabetes in primary care: a qualitative study of patient views. Int J Nurs Stud 2011;48:37-46.

49 Ross LJ, Byrnes A, Hay RL, et al. Exploring the highs and lows of very low carbohydrate high fat diets on weight loss and diabetesand cardiovascular disease-related risk markers: a systematic review. Nutr Diet 2021:78:41-56.

50 Greaves CJ, Sheppard KE, Abraham C, et al. Systematic review of reviews of intervention components associated with increased effectiveness in dietary and physical activity interventions. BMC Public Health 2011;11:119.

51 Pearson A, Wiechula $R$, Court A, et al. A re-consideration of what constitutes "evidence" in the healthcare professions. Nurs Sci $Q$ 2007;20:85-8.

52 Fraser S, Moore D, Keane H. Habits: Remaking addiction. UK: Palgrave Macmillan, 2014

53 Churuangsuk C, Kherouf M, Combet E, et al. Low-carbohydrate diets for overweight and obesity: a systematic review of the systematic reviews. Obes Rev 2018;19:1700-18. 